We try to publish authors' responses in the same edition with readers' comments. Time constraints might prevent this in some cases. The problem is compounded in a bimonthly journal where continuity of comment and redress are difficult to achieve. When the redress appears 2 months after the comment, 4 months will have passed since the article was published. Therefore, we would suggest to our readers that their correspondence about published papers be submitted as soon as possible after the article appears.

\section{Narcotic Theft}

To the Editor: We report a case of narcotic theft by a man who disguised himself as a visiting home nurse at a patient's home.

Our patient was an 89-year-old woman who had sustained a right femoral neck fracture 20 months previously. Severe coronary artery disease found by angiography precluded surgery. The patient was cared for at home and was receiving one tablet of hydrocodone bitartrate $5 \mathrm{mg}$ with acetaminophen $500 \mathrm{mg}$ (Vicodin) each night for the last 17 months. She was living with her daughter, who was in regular communication with our clinic. The patient also was receiving cardiac medications for heart failure, warfarin for life-long anticoagulation, and thyroxine for hypothyroidism. Patient had regular follow-up with home nurse visits, home physician visits, and periodic visits at our clinic and an orthopedist's office. The patient had an excellent compliance record for all her medications, and she never requested tablets of hydrocodone in addition to those regularly prescribed to her.

One day a man appeared at the patient's home identifying himself as a visiting home nurse. The patient wondered about the visiting nurse coming to her home on that particular day because no such visit was previously scheduled. She nonetheless admitted the impostor into her home. The intruder told the patient that he had come to check on her medications. He then examined all the medication bottles and told her that because she was on so many costly medications, he could get the hydrocodone for her free. The intruder also assured the patient that although he would take the current amount of hydrocodone in the bottle with him, he would refill the prescription and return with additional tablets of hydrocodone at no charge to the patient. The intruder did not take any other medication bottles with him. Obviously the intruder never returned. When the patient's daughter arrived home after work and learned about the incident, she immediately surmised that the man was a thief and called our clinic and the police to report the theft.

The reason the thief targeted our patient's home is unknown. He might have become aware that our patient was taking narcotic pain medications, or he might just have been targeting homes with a wheelchair access to find patients who might be taking narcotic medications. Sadly the patient died from a sudden cardiac arrest at home 2 weeks after the incident.

Our case illustrates yet another shrewd method of stealing narcotics. To our knowledge, this method has not previously been reported. Our case should serve as a reminder that patients should be advised not to let unscheduled visiting nurses into their home. When a visiting nurse does arrive at the house, the patient should ask for the name to establish that the visiting nurse has been previously scheduled before letting that person into the house. This recommendation should prevent or minimize narcotic theft and possibility of personal danger to the fragile and ill patients living at home.

Ram Kakaiya, $\mathrm{MD}$ Jennifer Wenzel-Wamhoff, PharmD University of Illinois Primary Care Clinic Rockton, Ill

\section{Hormonal Therapy and Management of Premenstrual Syndrome}

To the Editor: I was pleased to see an article by a family physician on this very important topic. ${ }^{1}$ Premenstrual syndrome (PMS) is more common than is thought, and there are no good studies that have tried to elucidate its prevalence, age at onset, and natural history. Very little is known about the neurohormonal mediators as well. Even so, it remains a common condition that affects young reproductive-age women.

This article discusses the use of hormonal therapy in the management of PMS. Schmidt et al $^{2}$ suggest that PMS might represent an abnormal response to normal hormonal changes. FitzGerald et $\mathrm{al}^{3}$ conclude that premenstrual dysphoric disorder appears to be associated with serotonergic deficiency. High concentrations of luteal phase estradiol and luteinizing hormone are related to the severity of premenstrual symptoms.

Halbreich ${ }^{4}$ discusses the possibility of internationally recognized interdisciplinary diagnostic criteria for PMS. PMS can be preceded by a prodromal aura. The fourth edition of the Diagnostic and Statistical Manual of Mental Disorders defines PMS as different from a premenstrual dysphoria disorder or luteal phase dysphoric disorder and late luteal phase dysphoria disorder. It might be possible to categorize the variety of symptoms as (1) PMS with primary mood disorder, (2) PMS with fluid retention, (3) PMS with musculoskeletal symptoms, eg, arthralgia, myalgia, and (4) PMS with generalized symptoms eg, fatigue, headaches, and breast tenderness.

Therapy for this disease could be targeted to the actual symptoms and started at the first indication of aura. General measures are to encourage a healthy lifestyle, exercise, and a balanced diet. The commonest medications used are pain relievers. ${ }^{5}$ One way to prevent PMS might be to use oral contraceptive pills to eliminate for- 
mation of the corpus luteum, which is essential for the symptoms of PMS. Dietary modification with highcarbohydrate diet, calcium supplementation, ${ }^{6}$ and decreased caffeine could be helpful in preventing PMS. Depending on the type of PMS the patient has, appropriate therapy could be initiated.

The use of selective serotonin reuptake inhibitors (SSRIs) has been investigated in PMS treatment. ${ }^{7-11}$ Tiemstra did not mention periodic and continuous therapy as an option. In our practice we find that PMS with aura can often be treated with a periodic use of SSRI about 10 days before the menstrual period or during the luteal phase. Patients with no aura can be cycled on the SSRI to coincide with the luteal phase. Continuous use of SSRI is warranted if depressive symptoms persist 4 days after onset of menstrual bleeding.

The patient can derive most benefit from appropriate use of diagnostic skills combined with individualized therapy.

Niharika Khanna, MD University of Maryland School of Medicine Baltimore

\section{References}

1. Tiemstra JD, Patel K. Hormonal therapy in the management of premenstrual syndrome. J Am Board Fam Pract 1998;11: 378-81.

2. Schmidt PJ, Nieman LK, Danaceau MA, Adams LF, Rubinow DR. Differential behavioral effects of gonadal steroids in women with and in those without premenstrual syndrome. $\mathrm{N}$ Engl J Med 1998;338:209-16.

3. FitzGerald M, Malone KM, Li S, Harrison WM, McBride PA, Endicott J, et al. Blunted serotonin response to fenfluramine challenge in premenstrual dysphoric disorder. Am J Psychiatry 1997;154:556-8.

4. Halbreich U. Menstrually related disorders - towards interdisciplinary international diagnostic criteria. Cephalalgia 1997;17(Suppl 20):1-4.

5. Singh BB, Berman BM, Simpson RL, Annechild A. Incidence of premenstrual syndrome and remedy usage: a national probability sample study. Altern Ther Health Med 1998;4(3):75-9.

6. Thys-Jacobs S, Starkey P, Bernstein D, Tian J. Calcium carbonate and the premenstrual syndrome: effects on premenstrual and menstrual symptoms. Premenstrual Syndrome Study Group. Am J Obstet Gynecol 1998;179:444-52.

7. Yonkers KA. Antidepressants in the treatment of premenstrual dysphoric disorder. J Clin Psychiatry 1997;58(Suppl 14):4-10, discussion 11-3.

8. Steiner M, Korzekwa M, Lamont J, Wilkins A. Intermittent fluoxetine dosing in the treatment of women with premenstrual dysphoria. Psychopharmacol Bull 1997;33:771-4.

9. Halbreich U, Smoller JW. Intermittent luteal phase sertraline treatment of dysphoric premenstrual syndrome. J Clin Psychiatry 1997;58:399-402.

10. Yonkers KA, Halbreich U, Freeman E, Brown C, Endicott J, Frank E, et al. Symptomatic improvement of premenstrual dysphoric disorder with sertraline treatment. A randomized controlled trial. Sertraline Premenstrual Dysphoric Collaborative Study Group. JAMA 1997;278:983-8.
11. Young SA, Hurt PH, Benedek DM, Howard RS. Treatment of premenstrual dysphoric disorder with sertraline during the luteal phase: a randomized, double-blind, placebo-controlled crossover trial. J Clin Psychiatry 1998;59:76-80.

\section{Reimbursement for Flexible Sigmoidoscopy}

To the Editor: I am a family physician currently in prac-3 tice in northeast Maryland. I enjoyed Dr. Rodney's edi- -0 torial exploring the possible reasons why flexible sig moidoscopy has not received widespread acceptance among physicians in general and family physicians in particular (Rodney WM. Will virtual reality simulators? end the credentialing arms race in gastrointestinal en $-\overline{\bar{c}}$ doscopy or the need for family physician faculty with endoscopic skills? J Am Board Fam Pract 1998; 11:492-잉 $5)$. His reasoning is good, but he misses the major reason why we don't routinely perform the procedurelack of reimbursement. These sigmoidoscopes are not inexpensive, and most insurers are unwilling to providen more than a pittance for performing a procedure thato will take $\mathbf{4 5}$ minutes, including setup and cleaning. I do not own a sigmoidoscope; in the past I used the hospital $i_{\vec{N}}$ equipment. I have since stopped, as managed care com-iv panies would rather I refer the patient to a gastroen- $\vec{\infty}$ terologist who does own the sigmoidoscope, thus avoid- $\vec{\circ}$ ing a room charge at the hospital. In the time it would? take me to perform the procedure, I can see 4 to $6 \mathrm{pa}-\overrightarrow{-}$ tients. I am not adverse to doing procedures; I performo skin biopsies and vasectomies in my office, and I have an active intensive care practice in the hospital.

At a recent managed care workshop it was noted that: the behavior you reward is the behavior you get. Offer- 0 ing flexible sigmoidoscopy, as currently reimbursed, is as losing proposition and a poor business decision. I refer my patients to another physician for this procedure, at least those I can convince to pursue the test.

John R. Mulvey, $M \mathrm{DD}_{\overrightarrow{\mathrm{O}}}^{\overrightarrow{\mathrm{F}}}$ Elkton, $M \mathrm{~d} \rightrightarrows$

\section{Role of Balint Groups in Caring for Patients With Unexplained Symptoms}

To the Editor: We wish to comment on "Understanding. and Caring for the Distressed Patient With Multipleo Medically Unexplained Symptoms" by Walker et al. ${ }^{1 / 3}$ We agree with many of the concepts presented in the paper, and the way in which the P-P-P model is developed and related to clinical practice is excellent. Nevertheless, we find it unfortunate that the reference to $\widetilde{N}$ the work of Michael Balint is limited to mentioning $\frac{\text { I }}{3}$ Balint groups as "an example of physician support groups."

Through his work with general practitioners in the United Kingdom, Michael Balint pioneered the investigation of how primary care providers effectively deal with patients who complain of unexplained somatic $\stackrel{\oplus}{9}$ symptoms. Although based on observations gathered 0 with physicians 40 years ago, Balint's seminal work The Doctor, His Patient and the Illness ${ }^{2}$ introduces concepts that are echoed by Walker et al. These include the $\stackrel{\mathbb{Q}}{\varrho}$ complex interaction between psychosocial factors and? 